Tamayo, C. \& Valle, J. (2020). Desterritorializando a escola como a gente a conhecia: perspectivas socioculturais da Educação Matemática no contexto da Pandemia. Revista Latinoamericana de Etnomatemática, 13(1), 1-5. DOI: 10.22267/relatem.20131.57

\title{
EDITORIAL
}

\section{Desterritorializando a escola como a gente a conhecia: perspectivas socioculturais da Educação Matemática no contexto da Pandemia}

(Versión en español mas abajo)

\author{
Carolina Tamayo ${ }^{1}$ \\ Julio Valle ${ }^{2}$
}

Ao menos 192 países do mundo fecharam, desde março de 2020, as suas escolas públicas e particulares, como uma medida para conter o avanço da pandemia provocada pelo novo coronavírus COVID-19. Mais de 1,5 bilhão crianças e jovens estão em casa segundo monitoramento realizado pela Organização das Nações Unidas para a Educação, a Ciência e a Cultura (Unesco). O contexto que se delineia a partir dessas medidas, necessárias para evitar a propagação ainda mais rápida do vírus, sinaliza, no âmbito de um futuro ainda incerto, implicações bastante relevantes para o cenário educacional.

Sob essa perspectiva, este volume especial é um espaço que reúne reflexões de pesquisadores convidados para problematizar e desestabilizar esse território chamado 'escola' ou 'classe de Matemática' que, pautado pelo desejo de manter em funcionamento os dispositivos disciplinares que organizam a aprendizagem e ensino, tem gerado novas demandas para todos os sujeitos vinculados de uma outra forma à educação.

Diante do futuro e dos contextos educacionais ainda incertos que se desenham no horizonte e certos de que as perspectivas socioculturais da Educação (Matemática) podem contribuir, devido à natureza de sua preocupação fundamental, este volume contribui com o

\footnotetext{
${ }^{1}$ Doutora em Educação pela Universidade Estadual de Campinas (UNICAMP). Professora da Faculdade de Educação da Universidade Federal de Minas Gerais (Brasil) e integrante do Grupo de Pesquisa e Estudo interinstitucional inSURgir da mesma universidade. Integrante do Grupo de Pesquisa Educação, Linguagem e Práticas Culturais (UNICAMP) e do Grupo de Pesquisa Matemática, Educación y Sociedad (Universidad de Antioquia, Colômbia). Coordenadora para Suramérica da Red Internacional del Etnomatemática. E-mail: carolinatamayo@ufmg.br.

${ }^{2}$ Doutor em Educação pela Universidade de São Paulo (USP). Professor do Instituto de Matemática e Estatística da USP (Brasil). Membro do Grupo de Estudos e Pesquisas em Etnomatemática da Faculdade de Educação da USP (GEPEm). Ex-Secretário Municipal de Educação e Cultura de Pindamonhangaba (2017-2020), cidade natal. E-mail: julio.valle@ime.usp.br
} 
aprofundamento do debate sobre urgentes questões que têm emergido ou se intensificado neste momento: qual o papel social da educação em tempos de isolamento social e após o fim deste?; Como mobilizar a matemática no escopo de um projeto social, tanto quanto educacional, em permanente redefinição?; Qual a pertinência do ensino remoto considerando as condições materiais de sobrevivência de grande parte das famílias que vivem em contextos de desigualdade social e vulnerabilidade?; como as perspectivas socioculturais da educação Matemática respondem às demandas emergentes? que escola é essa que acontece em tempos de isolamento social?; será possível que outras matemáticas aconteçam em tempos de pandemia e que ampliem a visão de educação ligada a modelos de produção capitalista?; Qual é ou quais são papel(is) da educação matemática na explicação da pandemia e das alternativas de enfrentamento? Muitos modelos e simulações aparecem a cada dia em jornais, chats e redes sociais, mas temos gerado ou podemos gerar na escola enfoques para uma cidadania crítica e consciente em relação à crise? Quais os desafios e as possibilidades que se anunciam para a educação do campo, a educação ribeirinha, indígena e quilombola? Que teorias, epistemologías e conceitos podem ser mobilizados no movimento de responder às perguntas sobre educação e ensino de Matemática que emergem desse novo contexto?

Apostamos na potencialidade deste dossiê para trazer respostas às questões formuladas por percebê-lo como uma contribuição inédita e legítima de pesquisadoras e pesquisadores latino-americanos da Educação Matemática. O dossiê, neste sentido, reúne trabalhos que nos sinalizam entraves, obstáculos e dificuldades, mas, especialmente, também possibilidades e alternativas propostas por diferentes perspectivas do Sul Global diante dos danos que vêm sendo causados pela maior crise sanitária que já experimentamos no século XXI.

Os pesquisadores e as pesquisadoras que aceitaram o convite de escrever para este dossiê demarcam importantes pautas de debate com base em olhares críticos ou decoloniais, também denotados pela variedade de epistemologias e enfoques teórico-metodológicos mobilizados nos textos abrem margem para pensar nos efeitos que, as novas formas de organização escolar provocaram e provocam em estudantes, familiares, professores e pesquisadores que, confinados em casa tiveram que enfrentaram e enfrentam a cada dia mudanças frenéticas, que sem dúvida alguma, tem sido muito mais complexas para o Sul Global, considerando suas condições sociais, políticas, econômicas e históricas. 
Tamayo, C. \& Valle, J. (2020). Desterritorializando a escola como a gente a conhecia: perspectivas socioculturais da Educação Matemática no contexto da Pandemia. Revista Latinoamericana de Etnomatemática, 13(1), 1-5. DOI: 10.22267/relatem.20131.57

Esta coletânea, mais do que reunir textos e respostas para a Educação Matemática, pode ampliar nosso campo de visão para questionar o que será da Educação a partir de agora. Afinal, o que é esse normal a que se espera voltar após da pandemia ter paralisado o mundo, suspendido nossas provisórias certezas e ter causado, até a presente data, cerca de novecentos mil óbitos? Certos de que os danos e prejuízos causados não serão facilmente superados, à Educação Matemática cabe também buscar, reconhecer e consolidar caminhos para contribuir com projetos emancipatórios de reconstrução social. Nessa direção, articulam-se as perspectivas e epistemologias do Sul da/para a Educação Matemática contidas nessas páginas.

Que estes textos possibilitem novas trilhas, novas linhas de fuga, novos afetos e efeitos em todes vocês. Boa leitura!

\section{Desterritorializando la escuela tal como la conocíamos: perspectivas socioculturales de la Educación Matemática en el contexto de la Pandemia}

Desde marzo de 2020, al menos 192 países en el mundo han cerrado sus escuelas públicas y privadas como medida para contener el avance de la pandemia provocada por el nuevo coronavirus COVID-19. Más de 1.500 millones de niños y jóvenes están en casa según el seguimiento que realiza la Organización de las Naciones Unidas para la Educación, la Ciencia y la Cultura (Unesco). Este contexto se desprendió de las medidas tomadas para evitar que el virus se propagara aún más rápido de forma mundial, apuntando un futuro incierto, y con importantes implicaciones para el escenario educativo.

Desde esta perspectiva, este número especial es un espacio que reúne las reflexiones de investigadores invitados a problematizar y desestabilizar este territorio denominado 'escuela' o 'clase de Matemáticas', que ha buscado mantener en funcionamiento los dispositivos

disciplinarios que organizan el aprendizaje y la enseñanza a través de la enseñanza remota, al mismo tiempo que ha generado nuevas demandas para todos los sujetos vinculados de una u otra manera a la educación. 
De cara al futuro y frente a los contextos educativos aún inciertos que se vislumbran en el horizonte y, seguros de que las perspectivas socioculturales de la Educación (Matemática) pueden contribuir, por la naturaleza de su preocupación fundamental, este número permite profundizar los debates sobre cuestiones urgentes que han surgido o que se han intensificado en este momento: ¿Cuál es el papel social de la educación en tiempos de aislamiento social y después de su fin?; ¿Cómo movilizar las matemáticas en el ámbito de un proyecto social, así como educativo, en permanente redefinición?; ¿Cuál es la relevancia de la educación a distancia, considerando las condiciones materiales de supervivencia de la mayoría de las familias que viven en contextos de desigualdad social y vulnerabilidad?; ¿Cómo responden las perspectivas socioculturales de la Educación Matemática a las demandas emergentes?; ¿Qué escuela es esa que acontece en tiempos de aislamiento social?; ¿Es posible que otras matemáticas ocurran en tiempos de pandemia y ampliar la visión de la educación ligada a modelos de producción capitalista?; ¿Cuál es o cuáles son los papel(es) de la educación matemática en la explicación de la pandemia y las alternativas de afrontamiento?; Muchos modelos y simulaciones aparecen todos los días en periódicos, chats y redes sociales, pero ¿Hemos generado o podemos generar enfoques en la escuela para una ciudadanía crítica y consciente con relación a la crisis?; ¿Cuáles son los desafíos y posibilidades que se están anunciando para la educación rural, ribereña, indígena y quilombola?; ¿Qué teorías, epistemologías y conceptos se pueden ubicar en el movimiento de responder preguntas sobre educación y enseñanza de las Matemáticas que surgen de este nuevo contexto?.

Creemos en el potencial de este dossier para dar respuesta a las preguntas formuladas, al percibirlo como un aporte inédito y legítimo de los investigadores latinoamericanos en Educación Matemática. El dossier, en este sentido, recoge trabajos que señalan obstáculos y dificultades, pero, sobre todo, también posibilidades y alternativas propuestas por diferentes perspectivas del Sur Global ante los daños que ha provocado la mayor crisis de salud que ya vivimos en el siglo XXI.

Los investigadores e investigadoras que aceptaron la invitación a para participar este dossier marcaron importantes pautas de debate, basados en visiones críticas o decoloniales, también denotadas por la variedad de epistemologías y enfoques teóricos y metodológicos movilizados en los textos que abren el campo para pensar sobre los efectos que, las nuevas 
Tamayo, C. \& Valle, J. (2020). Desterritorializando a escola como a gente a conhecia: perspectivas socioculturais da Educação Matemática no contexto da Pandemia. Revista Latinoamericana de Etnomatemática, 13(1), 1-5. DOI: 10.22267/relatem.20131.57

formas de organización escolar han provocado y provocan a estudiantes, familias, docentes e investigadores que, confinados en sus hogares, han tenido que afrontar y afrontan cada día cambios frenéticos, que sin duda han sido mucho más complejos para el Sur Global, considerando sus condiciones sociales, políticas, económicas e históricas.

Esta colección, más que recopilar textos y traer respuestas para la Educación Matemática, puede ampliar nuestro campo de visión para cuestionarnos ¿Qué será de la Educación a partir de ahora? Al fin y al cabo, ¿Cuál es esa normalidad que se espera que vuelva después de la pandemia que ha paralizado al mundo, suspendido nuestras certezas provisionales y ha provocado, hasta la fecha, unas novecientas mil muertes? Seguros de que los daños y perjuicios causados no serán fácilmente superados, la Educación Matemática también debe buscar, reconocer y consolidar formas de contribuir a proyectos emancipadores de reconstrucción social. En esta dirección, se articulan las perspectivas y epistemologías del Sur de/para la Educación Matemática contenidas en estas páginas.

Que estos textos permitan nuevos caminos, nuevas líneas de fuga, nuevos afectos y efectos en todos ustedes. ¡Buena lectura! 